\title{
O Currículo como Forma
}

[Curriculum as Form]

\section{Silvio Ricardo Gomes Carneiro円}

Resumo: Desenvolvemos nesse artigo um debate no campo da teoria do currículo. Partimos da perspectiva de que o currículo não é apenas um cardápio de conteúdo a ser transmitido, mas uma forma. Com isso, provocamos um novo lugar do currículo vinculado aos campos de luta tão próprios à educação. Significa, pois, pensar o currículo como parte de relações políticas e estéticas. Isto é, o currículo é efeito de poder, território de disputas, mas também espaço para uma forma de vida, estética de existência. Com isso, compreende-se nas lutas políticas seus elementos estéticos e educacionais. Mas também, não há movimento educacional sem bases no caldo de movimentos políticos e culturais. Nesse sentido, o artigo contraria o reflexo imediato de pensar o currículo a partir do seu conteúdo. Provocamos a pensar o currículo como forma, possibilidade de uma arquitetura para uma nova forma social.

Palavras-chave: currículo; forma; estética; política; educação.

Abstract: This paper develops arguments in the theory of curricula. Contrary to a perspective of curricula as a source of knowledge to be handed down, we will think curricula as a form. As a consequence, we develop a new locus for the curricula joined to the usual battlefields in education. That is, curricula would be part of political and aesthetic relationships. It means to declare on the one hand curricula as an effect of power, a social question to contest; and, on the other hand, a place for forms of living, aesthetics of existence. Then, we can consider the aesthetic and educational elements within political struggles as well as the educational movements based in the political and cultural movements. In this sense, this paper opposes the immediate thinking that considers curricula as a content. We are aiming to think curricula as a form, considering the architecture of a new social form.

Keywords: curricula; form; aesthetics; politics; education.

\footnotetext{
${ }^{\star}$ Professor Adjunto do curso de Licenciatura em Filosofia do CCNH/UFABC e dos programas de Mestrado Profissional e Acadêmico em Filosofia da UFABC. Atualmente desenvolve pesquisa no projeto "Política Educacional na Rede Estadual Paulista”, financiado pela FAPESP (Processo 2018/09983-0). E-mail: silvio.carneiro@ufabc.edu.br. ORCID: https://orcid.org/0000-0002-4322-2207.
} 
Ver o currículo como representação implica expor e questionar os códigos, as convenções, a estilística, os artifícios, por meio dos quais ele é produzido: implica tornar visiveis as marcas de sua arquitetura.

Tomaz Tadeu da Silva, O currículo como fetiche

\section{Introduções}

Uma boa maneira de se iniciar o debate que articula estética, política e educação parte da compreensão realizada pelos movimentos de educação articulada às manifestações culturais e políticas de movimentos estudantis, de gênero ou mesmo antirracistas que povoam os discursos sociais das políticas contemporâneas. Retomaríamos aqui as frases lançadas nas ruas, aquelas proferidas pelos estudantes que reivindicam o poder à imaginação, aos corpos em suas mais diversas manifestações de sexualidade e raça. Aqui, política e estética se acompanham e se fortalecem uma vez que nesta relação se fazem ouvidas vozes inauditas no espaço público (para não dizer que sempre foram silenciadas). As estratégias traçadas pelas vias estético-políticas aguçam os sentidos para uma "nova sensibilidade" 1, atenta para os "roncos surdos da batalha" 2$]_{3}^{3}$

Proponho aqui alterar um pouco esta fotografia. Denominei este ensaio como "o currículo como forma” para pensarmos este

\footnotetext{
${ }^{1} \mathrm{O}$ termo aqui tem clara referência à concepção de Marcuse para uma "nova sensibilidade", tal como desenvolvido em An Essay on Liberation. Erroneamente compreendida como uma oposição romântica a toda forma racional, Marcuse concebe a sensibilidade na novidade de seu tempo, marca que aparece nos corpos e nos discursos dos grupos sociais que se rebelam contra o status quo mediante uma mudança de posição de nossas estruturas subjetivas, em que "ao invés de ser formada e permeada pela racionalidade da dominação, a sensibilidade seria guiada pela imaginação, mediando entre as faculdades racionais e as necessidades sensíveis" (MARCUSE, 1969, p. 30).

${ }^{2}$ A referência aqui vem de Foucault, que ao fim de seu Vigiar e Punir, ao descrever os dispositivos de saber-poder no que se configurou como os institutos prisionais da Modernidade, lança uma última aposta: "Nessa humanidade central e centralizada, efeito e instrumento de complexas relações de poder, corpos e forças submetidos por múltiplos dispositivos de 'encarceramento', objetos para discursos que são eles mesmos elementos para essa estratégia, temos que ouvir o ronco surdo das batalhas” (FOUCAULT, 1977, p. 269).

${ }^{3}$ Uma observação a mais nessa passagem: parece estranha esta conjugação entre Foucault e a "nova sensibilidade" de Marcuse. Como descrito na nota anterior, a reflexão marcuseana a respeito de uma nova sensibilidade parece inscrita na estratégia da "hipótese repressiva" que Foucault rejeita enquanto reflexo da estrutura de poder pensada na dualidade de um poder positivo e outro negativo, reprimido. De fato, o estranhamento procede e valeria a pena uma investigação mais detida. Contudo, devo lembrar que tanto Marcuse quanto Foucault desenvolvem, cada qual a seu modo, uma "estética da existência" nos termos de Foucault, um ethos estético nos termos de Marcuse. Desenvolvi um pouco mais esta aproximação em outro artigo (CARNEIRO, 2019).

${ }^{4}$ Este ensaio é fruto de uma conferência realizada na UnB com o tema "Estética e Política na América Latina", realizada no I Simpósio Internacional de Humanidades da UnB, realizado entre os dias 21 e 23 de outubro de 2019. O tema geral do simpósio, "A relevância social da universidade pública" motivou a provocação para pensar dispositivos da educação em meio ao campo estético-político. O resultado foi esta apresentação cujo título parafraseia a
} 
jogo a partir do terreno acadêmico que pisamos. 4 Pretendo com isso ressaltar elementos que por vezes a imagem maior das lutas sociais em campos culturais e educacionais deixa de lado. Pensar o currículo como forma significa retirar implicações das manifestações estético-políticas no território da construção de conhecimento, refletindo um pouco mais sobre os termos em que nossa sensibilidade política é afetada por aquilo que denominamos currículo.

Antes de avançarmos para uma discussão mais detida sobre o sentido de "currículo", uma observação se faz necessária. Que relação pode ter a academia - que nos parece muitas vezes um projeto de reprodução ideológica das elites, distante e por vezes configurada em uma torre de marfim - com os vínculos populares gerados no encontro da estética com a política? Tudo e nada, ao mesmo tempo. Uma universidade cada vez mais "operacional", de ensino e resultados tecnicistas e instrumentais 5 acompanha o estranhamento usual ao aproximar universidade, política e cultura. Universidade, dizem, não é lugar de se fazer política ou "balbúrdias" culturais. Assim, mesmo as culturas política e artística que aparecem no terreno acadêmico por vezes caracterizam a distância do discurso popular das ruas, em defesa de determinada "elite" (esta sim, produto do imaginário do "cidadão de bem") autolegitimando-se pela eficiência tecnológico-científica de seus saberes. As imagens de uma "torre de marfim" ou de "fábrica de diplomas" se abraçam em uma estética, portanto. Cada qual com sua forma: centros de excelência ou educação massificada ocupando um espaço distante das contradições sociais em que vivem. Ambas, imagens refletidas da mesma política de exclusões.

No entanto, não é sem exagero dizer que não há um movimento político-cultural que não tenha no horizonte um projeto de educação. Mesmo a imagem da torre de marfim das instituições de elite se apoia nesta perspectiva estéticopolítica de uma sociedade dividida por classes sociais e exige uma distância para se autolegitimar como fonte segura de saber. Em contrapartida, a história dos movimentos sociais no Brasil tem mostrado constantemente que o horizonte educador se faz fundamental para consolidar suas bandeiras. Dele surge uma nova me-

reflexão adorniana "Ensaio como Forma", no qual a fina análise permite notar quanto estética, política e educação estão imbricados em um potente jogo crítico.

${ }^{5}$ Ver CHAUI, “Contra a Universidade Operacional” (In: CHAUI, 2018) e SILVA, 2014. 
dicina, uma nova engenharia, um novo campo de direitos e não menos importante, um novo campo discursivo para se fazer visível e preparar o combate contra a barbárie que aflige suas culturas. Este é o embate que se trava na educação quando se traz as questões de gênero à tona, quando um livro de história narra o sangue da escravidão, quando na geografia descobrimos que o cerrado não é um território infértil, mas extremamente rico e povoado de culturas. Em outras palavras, todo projeto estético-político tem um horizonte educacional.

Mas também o contrário: toda educação incide em horizontes estético-políticos. A imagem da torre de marfim é parte disso: nesta ideologia burguesa, é preciso criar uma arquitetura que separe a elite da dita "ralé". Mas também, e aqui podemos notar outras arquiteturas (e a UnB é conhecida nesse sentido) da construção de prédios e corredores em que os conhecimentos se visitam (ou deveriam fazê-lo); em que artes e engenharias não seriam universos distantes, mas parte de uma mesma "universidade". $\mathrm{Ou}$ ainda, em anos mais recentes, quando na ocupação das escolas em 2015, formatos diversos de sala de aula são apresentados (na verdade, recuperados, se lembrarmos a disposição para o diálogo de Paulo Freire e os círculos de cultura), como o formato em círculo, mais propício para um formato de conhecimento dialogado e nem sempre absorvido pela hierarquia de locorum discursivos..$^{6}$

Tais considerações preliminares entre educação, política e estética acompanham uma reflexão de Herbert Marcuse sobre a relação entre arte e política, quando este afirma: "nem arte política, nem politica como arte, mas arte como arquitetura de uma sociedade livre." (MARCUSE, 2007, p. 122). Em outras palavras, a relação marcuseana entre estética e política não adquire valor emancipatório sem que se consolide um espaço de libertação. Não será a arte como propaganda política (muito utilizada na comunicação panfletária presente nas guerras e guerrilhas ideológicas), nem a política estetizada (reforço das ideologias nos mais diversos regimes, em especial as grandes manifestações de massa no totalitarismo). Arte como arquitetura significa estabelecer um campo em que as linguagens emancipatórias circulem livremente, em que a alteridade seja vista como parte (estranha) do convívio - e não como um inimigo a ser colonizado ou extermi-

\footnotetext{
${ }^{6}$ Ver. CAMPOS et al., 2014.
} 
nado. Considero esta passagem fundamental para compreender com mais cuidado o que procuro apresentar na relação entre educação, política e estética e, sobretudo, no que pretendo argumentar sob a formulação do "currículo como forma".

Portanto, pretendo, a partir dos pressupostos de uma arquitetura para a emancipação, desenvolver uma noção de currículo como peça central nesta articulação. $\mathrm{O}$ sentido de currículo, de antemão, não se reduz à "organização de conhecimentos, habilidades e competências a serem transmitidos", mas que se lhe compreenda como "forma" "7, como "organização de materiais no espaço e no tempo" relativos à formação da experiência. Uma forma que, como sugeria Adorno, seja atravessada pelo material cultural e social e que expresse uma experiência (ADORNO, 2003). Como diria Tomás Tadeu da Silva, o currículo pode ser pensado como uma arquitetura (SILVA, 2001, p. 66). O que podemos pensar sobre o currículo neste sentido? O que Marcuse procura explicitar com essa arquitetura de uma sociedade livre? Seria a arquitetura curricular capaz de sustentar uma possibili- dade de liberdade?

\section{Universidade unidimensional}

A compreensão marcuseana da função crítica da arte como parte da "arquitetura da sociedade livre" se apresenta como frente àquilo que denominava uma sociedade unidimensional. Decerto, os escritos desse filósofo encontram nas formas estéticas a compreensão de uma nova racionalidade, distinta da racionalidade tecnológica que absorve em seus rankings de eficiência e produtividade os mais diversos tipos de conhecimento (mesmo críticos), tornando estéril qualquer forma de contestação, isolando de seus índices toda forma de produção de conhecimento que não seja produtiva e eficiente segundo os valores da sociedade. Para uma compreensão mais determinada, sigamos aqui a compreensão de Marilena Chaui sobre a "universidade operacional":

Regida por contratos de gestão, avaliada por índices de produtividade, calculada para ser flexível, a universidade operacional

\footnotetext{
${ }^{7}$ MASSCHELEIN \& SIMONS, 2007. Mas também, considero aqui a composição adorniana do ensaio como forma. Não se trata de um modelo idealista de forma (um formalismo), mas da forma como organização de materiais que compõem nossas experiências.
} 
está estruturada por estratégias e programas de eficácia organizacional e, portanto, pela particularidade e instabilidade dos meios e dos objetivos. Definida e estruturada por normas e padrões administrativos inteiramente alheios ao conhecimento e à formação intelectual, está pulverizada em micro-organizações que ininterruptamente ocupam seus docentes e curvam seus estudantes a exigências exteriores ao trabalho do conhecimento. A heteronomia da universidade é visível a olho nu: o aumento insano de horas-aula, a diminuição do tempo para mestrados e doutorados, a avaliação pela quantidade de publicações, colóquios e congressos, a multiplicação de comissões e relatórios etc. Voltada para seu próprio umbigo, mas sem saber onde este se encontra [uma torre de marfim construída nas nuvens?], a universidade operacional opera e por isso mesmo não age [apenas coloca a máquina para funcionar, a despeito de suas engrenagens enferrujadas]. Não surpreende então que esse operar co-opere para sua contínua desmoralização pública e degradação interna. 8

Esta conclusão de Chaui nos faz pensar muito sobre a atualidade das discussões sobre a universidade e sua relevância social. Atualmente, o questionamento sobre os saberes acadêmicos (na verdade, uma questão que passa de geração em geração - não seria essa a questão em 1968?) se reforça. No entanto, na medida em que as universidades passam por aquilo que Boaventura de Sousa Santos denomina "crise de legitimidade" (SANTOS \& ALMEIDA Fo., 2008), a saber: a tensão entre a formação para as artes e as ciências, de um lado, e a instrução e treinamento dos profissionais para o mercado. Em tempos neoliberais de uma universidade operacional, cada vez mais associa-se a universidade com a "fábrica de diplomas" ou, no pior dos casos, a um "mal necessário" para obter certificados no mercado de trabalho. Uma crise da legitimidade da instituição, portanto, que se reverte na crise ope-

${ }^{8}$ CHAUI, “Contra a Universidade Operacional”. In: CHAUI, 2018, p. 208. (nossos colchetes) 
racional da instituição - gerando projetos universitários os mais diversos, torres de marfim sobre nuvens de excelência.

Pensar o currículo como forma, no entanto, não significa alterar apenas pelos conteúdos os percursos epistemológicos que cada estudante seguirá. Lembremos aqui as conquistas que os movimentos sociais impuseram à comunidade acadêmica. Um exemplo interessante vem do movimento estudantil de Berkeley em 1968. Naquela época, os grupos de estudantes da comunidade negra e latino-americana procuraram responder à ausência de conteúdos em que as questões de sua comunidade estivessem implicadas em suas próprias trajetórias de conhecimento e cultura. Iniciaram, assim, um movimento para a criação de um College LumumbaZapata, em que os modelos de produção de conhecimento estivessem vinculados à narrativa das comunidades negra e latinoamericana, procurando reverter as "lacunas ideológicas" no interior do sistema universitário. O projeto não seguiu adiante naquele tempo, mas foi certamente fundamental para o que hoje conhecemos como Cultural Studies, refúgio para filosofias contemporâneas próprias ao pensamento dito "continental" (do ponto de vista americano, claro).
A partir de um "currículo como forma”, a questão passa a ser um pouco mais sobre o destino desse reconhecimento. Seria um reconhecimento de fato? Ou tal prestígio se vincula a uma arquitetura unidimensional em que os conhecimentos se categorizam no interior da oposição entre ciências duras e humanidades, filosofia analítica e filosofia continental, ciências altas e médias etc? Decerto, aqui não se quer retirar o valor das conquistas desses movimentos. A importância da perspectiva advinda desses movimentos para todos os campos de conhecimento (tecnológicos, biomédicos, culturais) revela apenas o fio de descobertas a serem feitas. O incômodo que gostaria de compartilhar surge quando tais estudos avançam sobre os limites da oposição integrada no interior da universidade operacional e unidimensional. Recolho aqui e ali algumas inquietações que surgem quando algo escapa desse campo, quando se apresentam alguns ruídos nas linhas curriculares traçadas na forma unidimensional desse currículo. Acompanho aqui as exclamações quando se propõe uma "matemática africana" ou uma "engenharia feminista". Aqui, parece que algo saiu fora do esquadro: já não existe o departamento de estudos culturais? Por que tratar disso na engenha- 
ria? A matemática não seria universal? Com estas interrogações, gostaria de voltar ao sentido do currículo como forma - pois estes são bons exemplos para elucidar quando Marcuse explicita a necessidade de uma arquitetura para uma sociedade livre: o currículo a ser pensado não apenas como componentes do saber, mas como estrutura em que os materiais são organizados, como numa obra de arte. Talvez aqui o vínculo entre educação, política e estética presente numa reflexão sobre o "currículo como forma" fique mais evidente.

Pensar o currículo como forma (e, consequentemente, no vínculo entre educação, estética e política) é impulsionar uma nova racionalidade que avance sobre os limites da universidade operacional. Recupero aqui um conceito de unidimensional sobre o qual fixamos o pensamento de Marcuse. O currículo como forma resiste à estrutura operacional. Na operação, os termos utilizados só fazem sentido no interior de operações heterônomas e servis a um modelo identitário de produção e eficiência. Daí, a ideia limitada da operação que só valoriza um conhecimento (seja ele técnico ou de humanas) que seja considerado "útil", aplicado. São úteis à criação de uma nova tecnologia, à manutenção de acervos, ou mesmo ao serviço social da universidade. A teorização crítica destas ações, no entanto, é vista como problemática, escapando da lógica de situações-problema a serem resolvidas. Na universidade operacional, cada departamento tem seu espaço (a despeito de uns terem menos espaços que outros - pois se reproduz a hierarquia no conflito de faculdades) e cada espaço, uma função.

Ultrapassar este campo é sair da lógica unidimensional, é contaminar o território dos saberes e, com efeito, é o avesso das funções departamentais. Matemáticas africanas e engenharias feministas são vistas como "vírus" no sistema, incompatíveis com a hierarquia das informações em trânsito nas operações. Caminho avesso ao que estou denominando "currículo como forma", cuja matriz estético-política disponibiliza os saberes em sua estrutura, não em sua funcionalidade.

\section{A forma e o currículo}

Compreendamos melhor esse movimento da forma. Conforme Tomás Tadeu da Silva, o currículo não é apenas o depósito epistemológico de saberes, mas nele estão implicadas "conexões entre saber, identidade e poder" (SILVA, 2014b, p. 16). Ora, para o au- 
tor, uma concepção crítica (ou pós-crítica) do currículo diverge da concepção tradicional de currículo em suas questões básicas. Enquanto na perspectiva tradicional a questão fundamental do currículo parte do conhecimento a ser "transmitido", nas perspectivas crítica e pós-crítica o viés será dado pelo "por quê?" e pelo "como?". Isso porque o próprio conhecimento a ser transmitido demonstra que todo documento curricular é um documento de poder. Isto é, o currículo é marcado por escolhas e decisões que determinam previamente a verdade de determinado saber. Conforme o autor,

o currículo é também uma questão de poder (...). Selecionar é uma operação de poder. Privilegiar um tipo de conhecimento é uma operação de poder. Destacar, entre as múltiplas possibilidades, uma identidade ou subjetividade como sendo a ideal é uma operação de poder. As teorias do currículo não estão, nesse sentido, situadas num campo 'puramente' epistemológico, de competição entre 'puras' teorias. As teorias do currículo estão ativamente envolvidas na ati- vidade de garantir o consenso, de obter hegemonia. As teorias do currículo estão situadas num campo epistemológico social. As teorias do currículo estão no centro de um território contestado (SILVA, 2014b, p. 16).

Pensar, pois, o currículo como forma remete a esse campo de poderes em que a organização de saberes está implicada. Poderes que, por sua vez, acompanham um discurso sobre a identidade e a subjetividade. Tomás da Silva afirmaria ainda que, nesse sentido, o currículo pode ser a organização de uma experiência subjetiva em relação com os campos de saber - o que confere à forma um sentido privilegiado. $\mathrm{O}$ currículo não ocorre a despeito da experiência subjetiva, não é um campo a que a experiência deve se submeter, mas sua materialidade existe em conexão com a própria experiência.

A partir daqui, considero o horizonte político e estético desta compreensão sobre o currículo. Do ponto de vista político, ressalto não apenas a questão do poder que o currículo traz em suas decisões, mas também nas relações que este carrega consigo. Quando Boaventura de Sousa Santos e Almeida Filho passam a refletir sobre a universi- 
dade do século XXI como uma "pluriversidade" (SANTOS \& ALMEIDA Fo, 2008, p. 41), algo da ordem do currículo como forma se materializa. O termo procura enfrentar os desafios de uma universidade em crise - crise gerada pela infiltração de valores próprios ao campo do mercado, heterônomos à produção do conhecimento acadêmico, como vimos na descrição da universidade operacional de Chaui. De outro modo, o conhecimento pluriversitário, conforme Santos e Almeida Filho,

é um conhecimento transdisciplinar que, pela sua própria contextualização, obriga a um diálogo ou confronto com outros tipos de conhecimento, o que o torna internamente mais heterogéneo e mais adequado a ser produzido em sistemas abertos menos perenes e de organização menos rígida e hierárquica (SANTOS \& ALMEIDA Fo, 2008, p. 41).

Seria fraco se partíssemos de uma noção transdisciplinar em que tudo se encaixe em tudo, em que os saberes não apresentassem seus critérios, seus limites e que, no fim das contas, ficassem reduzidos a um sentido pragmático de utilizar meios para obter determinado resultado. Não é isso que a crítica da pluriversidade traz consigo, uma vez que também critica esse empreendedorismo universitário das ciências sociais aplicadas por si mesmas, como meras técnicas sem qualquer envolvimento com as experiências e os limites em que estão implicadas.

Recupero aqui o sentido de estética, como sensibilidade para compreender melhor o sentido de forma em que o currículo - em uma hipotética pluriversidade estaria implicado. Trata-se de notar a estética como uma experiência sensível, que opera sobre os materiais do saber em uma nova arquitetura que não aquela determinada nas caixas departamentais ou no design vazio da mercadoria. Uma nova sensibilidade carregada de experiência vivida. Entender que a técnica não é uma mera aplicação de métodos, mas uma abertura para a experiência que conjuga, pois, uma subjetividade, uma ordem de poderes e, mais ainda, uma dimensão política. O currículo como forma opera neste campo: uma organização dos materiais em que a experiência esteja implicada. E, justamente por isso, o currículo é um ato político de antemão.

A partir desse ponto, trago o sentido de forma operado pela dupla de autores belgas, Jan Mass- 
chelein e Maarten Simons. Para os autores, a forma é um lugar em que a experiência é recuperada. Porque a forma é o lugar em que os materiais se organizam tendo em vista uma finalidade nela mesma, sua autonomia decorre da própria construção de seus conhecimentos. Como numa obra de arte, que se expressa como tal a despeito mesmo de suas finalidades, por vezes, a despeito mesmo de seus contextos históricos (como em clássicos da literatura). A obra de arte como forma se impõe como a ordem da experiência a despeito da pobreza da realidade em que se configura. Os materiais se organizam em uma maneira própria, apresentam uma linguagem e uma maneira de exprimir a experiência de modo singular, com suas contradições, com suas tensões e mesmo limites. A arquitetura que está implicada aqui é a arquitetura em que os materiais se relacionam.

Nesse sentido, o currículo como forma, lembrariam os nossos dois autores belgas, é sobretudo uma experiência de irrupção. Toda a arquitetura gerencial da produção de conhecimento, em que as universidades até então se mostram como grandes responsáveis, apenas restringe a experiência subjetiva ao campo técnico. No entanto, sabemos bem que a experiência subjetiva se mobiliza em outra sintonia: a técnica é apenas uma parte dessa dinâmica (talvez a mais enfraquecida desta).

O currículo como forma, pois, não se apresenta apenas pela disposição de conhecimentos transversais (o que pode ser mais um exercício de colonização de uma área ou setor da vida sobre os demais conhecimentos). Não há currículo sem experiência nele implicada. Aqui então se inicia outro processo para compreender as condições de possibilidade para que essa forma se desenvolva no currículo.

Pois a forma é uma construção contínua, um exercício de liberdade que não se estabelece $a$ priori. Pensemos o currículo como um ensaio: um exercício de experiência em relação com um objeto cultural. Os conteúdos de matemática não se restringem à ordem técnica desse saber. Há que se questionar pela razão de suas operações, por estratégias elegantes de raciocínio, pelo encontro com essa alteridade da linguagem peculiar à matemática e distinta das demais disciplinas. Tal movimento apresenta a subjetividade em seu exercício de liberdade, em sua experiência diante de determinada ordem do saber. 


\section{Breve Conclusão}

Finalizo aqui pensando mais a respeito disso. Pois a experiência da subjetividade está em relação constante com a ordem do saber, com a linguagem que lhe é estranha. O currículo não é um terreno certo, mas repleto de incertezas. Muitas vezes, procura-se apagar tais indeterminações com padrões de racionalidade que impedem à experiência falar por si mesma. A experiência, nesse caso, apenas reage ao choque, configurando-se uma pseudo-experiência. Esta pobreza sensível é o que orna a arquitetura hierárquica de poderes hoje: um tempo da experiência mutilada. Mas uma experiência não é um exercício de reação. $O$ que a estética nos ensina - e a política institucional poucas vezes tem ouvido para tanto - é que os materiais têm seu próprio tempo para se organizar.

Romper com essa reatividade é crucial. Significa impor um tempo próprio. Para tanto, a forma se impõe. Aos olhos do tempo acelerado e unidimensional contemporâneo, isso significa que a experiência se associa ao currículo quando se permite suspender o ritmo das coisas. Contrário ao tempo acelerado, é o tempo da suspensão que permite reconstruir todos os materiais históricos. Função fundamental em tem- pos difíceis como o nosso. Suspensão, pois, que não é o apagamento das mediações, mas a justaposição de suas relações. Movimento que não reduz o professor a um gestor do tempo de seus estudantes, mas o posiciona na responsabilidade de um mundo novo (ARENDT, 2016). É, de algum modo, colocar o objeto no coração da arquitetura curricular. Nessa arquitetura, encontros não devem ser estranhos, mas devem ser frequentes. O tempo, certamente, será outro - não será um ranking a avaliar o desempenho de determinado currículo.

Para que se suceda a experiência, a distância da ruptura se faz necessária. Encontrar o terceiro termo mediante uma suspensão do objeto. Eis aqui a possibilidade de notar os objetos e suas mais diversas atividades neles intrincadas: como o contexto de uma matemática de matriz africana. Só a proposição deste nome permite uma larga discussão sobre o sentido deste contexto e, não por menos, da própria matemática. Tal suspensão, pois, exige um outro tempo que não o acelerado em nosso cotidiano. Mas o tempo de estudo, de observação detida sobre os objetos. Isso requer um tempo como o tempo em que nos debruçamos sobre uma obra de arte.

Tal suspensão é, pois, ao mesmo 
tempo, um exercício de liberdade, a possibilidade de uma nova arquitetura que surge com os limites desta universidade na produção de saberes. A partir disso, cabem as tarefas: olhar a nossa própria forma, o modo como inseri- mos os saberes em conjunto; olhar o currículo como uma escrita de si, como um exercício de arte, como um observador de uma peça de arte que nos encanta. Diante dela, o material resiste, aguarda por ser profanado pela próxima geração.

\section{Referências}

ARENDT, Hannah. "A Crise na Educação”. In: ARENDT, Entre o Passado e o Futuro, trad. Mauro Barbosa, São Paulo: Perspectiva, 2016, p. 221-247.

ADORNO, Theodor. "O Ensaio como Forma". In: ADORNO, T., Notas de literatura - I, trad. Jorge de Almeida, São Paulo: Livraria Duas Cidades, Editora 34, 2003, pp. 15-46.

CAMPOS, Antonia et al. Escolas de luta, São Paulo: Veneta, 2016.

CARNEIRO, Silvio. "A estética como crítica: um debate entre Marcuse e Foucault". In: CD-Rom III Colóquio Nacional Michel Foucault, Política - Pensamento e Ação”, também disponível em: https://www.academia.edu/10812744/A_Est\% C3\% A9tica_como_Cr\% C3\% ADtica_Um_Debate _entre_Marcuse_e_Foucault. Visitado em 14/11/2019)

CHAUI, Marilena. Em Defesa da Educação Pública, Gratuita e Democrática. Belo Horizonte: Autêntica, 2018.

FOUCAULT, Michel. Vigiar e Punir: História da Violência das Prisões, trad. Raquel Ramalhete, $14^{\mathrm{a}}$ Edição, Petrópolis: Editora Vozes, 1977.

KELLNER, Douglas et al. Marcuse's Challenge to Education, New York: Rowman \& Littlefield Publishers, 2009.

MARCUSE, Herbert. An Essay on Liberation, Boston: Beacon Press, 1969. 2007 .

MASSCHELEIN, Jan \& SIMONS, Maarten. Em Defesa da Escola: Uma Questão Pública, Belo Horizonte: Autêntica, 2a Edição, 2007.

SANTOS, Boaventura de Sousa \& ALMEIDA Fo., Naomar. A universidade do século XXI: Para uma Universidade Nova, Coimbra: Almedina, 2008.

SILVA, Franklin Leopoldo e. Universidade, Cidade, Cidadania. São Paulo: Hedra, 2014.

SILVA, Tomás Tadeu da. O Currículo como Fetiche: a Poética e a Política do Texto Curricular, Belo Horizonte: Autêntica, 2001.

Documentos de identidade: uma introdução às teorias do currículo, $3^{\mathrm{a}}$ Edição, Belo Horizonte: Autêntica, 2014b.

Recebido: 14/11/2019

Aprovado: 18/12/2019

Publicado: $26 / 01 / 2020$ 
